OPEN ACCESS

Edited by:

Sami Akbulut,

Inönü University, Turkey

Reviewed by:

Tevfiktolga Sahin,

Inönü University, Turkey

Cemalettin Koc,

Inönü University, Turkey

*Correspondence:

Ji Chun Zhao

zhaojc3@163.com

Specialty section:

This article was submitted to

Vascular Surgery,

a section of the journal

Frontiers in Surgery

Received: 24 August 2021 Accepted: 09 December 2021

Published: 05 January 2022

Citation:

Chen WC, Wang Th, Yuan D and Zhao JC (2022) Multiple Splenic Artery

Aneurysms: A Case Report and

Review of the Literature.

Front. Surg. 8:763890

doi: 10.3389/fsurg.2021.763890

\section{Multiple Splenic Artery Aneurysms: A Case Report and Review of the Literature}

\author{
Wen Chun Chen, Tie hao Wang, Ding Yuan and Ji Chun Zhao* \\ West China Hospital, Sichuan University, Chengdu, China
}

Background: Multiple splenic artery aneurysms (MSAAs) are rare and there are few reports about their treatment. We herein present a rare case of MSAAs treated with splenectomy combined with endovascular embolization.

Methods: A 51-year-old female patient was incidentally diagnosed with MSAAs. Splenectomy combined with endovascular embolization was the chosen treatment.

Outcomes: The patient recovered uneventfully and was discharged from the hospital 5 days after splenectomy. The patient has been doing well during the 27 -months of follow-up.

Conclusion: Combined with the experience of the previous literature, we think splenectomy combined with endovascular embolization is a safe, reliable and minimally invasive treatment for some selected multiple SAAs, depending on several patient parameters, such as the age, sex, aneurysm dimension, aneurysm location, complications, and severity of the clinical findings.

Keywords: splenic artery aneurysms, splenectomy, aneurysmectomy, leukopenia, thrombocytopenia, endovascular embolization

\section{INTRODUCTION}

Splenic artery aneurysm (SAA) is the most common visceral aneurysm. It comprises about $60 \%$ of all visceral aneurysm cases and occurs predominantly in multiparous women and portal hypertension patients (1-3). The main risk factors for true SAAs are hypertension, atherosclerosis, liver cirrhosis, portal hypertension (PHT), liver transplantation, women, pregnancy and multiple pregnancies, with pregnancy and PHT being the most important risk factors $(1,2)$. The incidence of SAA was reportedly $7-50 \%$ in patients diagnosed as having cirrhosis and portal hypertension, and the incidence of PHT was reportedly $50 \%$ in SAA patients (1-5). Portal hypertension with SAA is common, whereas portal hypertension with multiple splenic artery aneurysms (MSAAs) is rarely. According to previous literatures, true MSAAs have an estimated prevalence rate of $0.02-0.1 \%$ (6). Despite the rarity of MSAAs, they are clinically important because their possible rupture may be catastrophic. Available methods for treatment of SAAs include endovascular, laparoscopic, and open surgery. However, the treatment of MSAAs is challenging for vascular surgeons. Herein we present a rare case of MSAAs treated with splenectomy combined with endovascular embolization and review the relevant literature. 


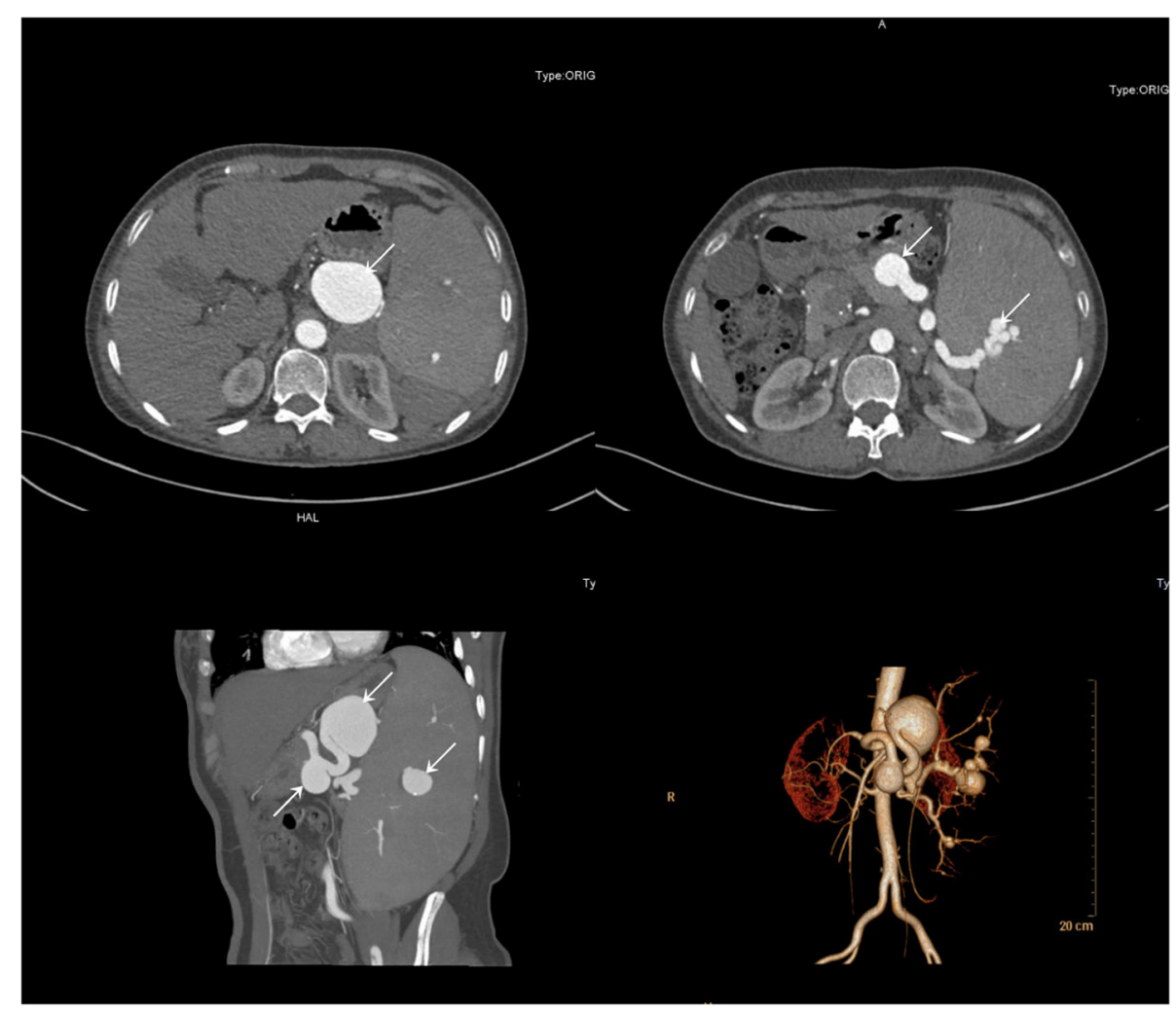

FIGURE 1 | Computerized tomography angiography demonstrated multiple aneurysms of the splenic artery.

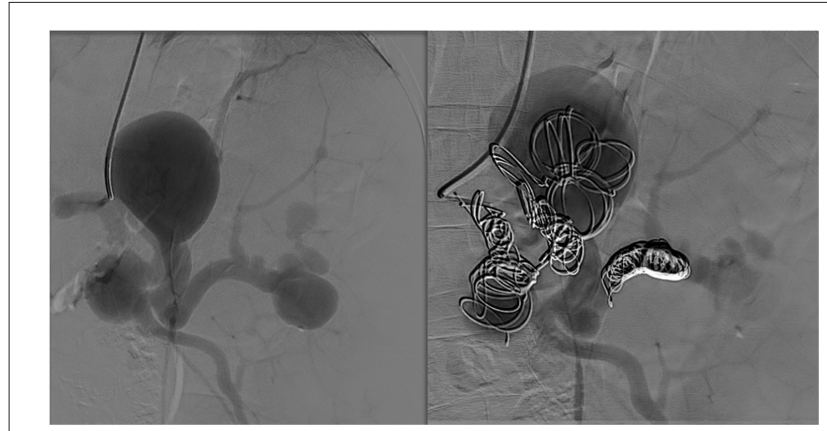

FIGURE 2 | Selective angiography showed that the blood flow to the spleen was significantly reduced.

\section{CASE REPORT}

A 51-year-old female patient with a negative abdominal physical examination was admitted to our hospital for multiple splenic artery aneurysms incidentally detected because of her presentation of occasional pain in her left ribs. Her past medical history showed that she was previously diagnosed as having chronic hepatitis B. She did not have any history of a genetically inherited disease and had never undergone a surgery. She had a history of two pregnancies. Her initial lab test results showed a hemoglobin level of $117 \mathrm{~g} / \mathrm{L}$, red blood cell count of $3.64 \times 10^{12} / \mathrm{L}$, white blood cell count of $1.82 \times 10^{9} / \mathrm{L}$, and platelet count of $20 \times 10^{9} / \mathrm{L}$, whereas all other laboratory test results were normal. Subsequently, a computed tomographic angiography showed multiple aneurysms of the splenic artery, and the largest aneurysm was $4.6 \times 3.5 \mathrm{~cm}$ (Figure 1). She was diagnosed with multiple splenic artery aneurysms, chronic hepatitis B, compensatory stage of liver cirrhosis, splenomegaly with hypersplenism, severe thrombocytopenia and portal hypertension. Considering the diameter of the aneurysms, the morphology of the aneurysms and splenomegaly with hypersplenism the treatment of aneurysmectomy plus splenectomy was obviously indicated. The patient has consented to the publication of the case details and images.

First, we performed endovascular embolization and subsequently monitored the patient's leukocyte and platelet counts. The selective splenic artery angiography confirmed the multiple aneurysms along splenic artery (Figure 1). Then, two of the larger aneurysms were selected for spring coil partial embolization, while the splenic hilum aneurysms and intra-splenic aneurysms were not treated. Meanwhile we also embolized the outflow tract of the largest aneurysm. The patient's postembolization angiogram showed that the blood flow in the aneurysmal sac had significantly reduced and slowed down (Figure 2). After-embolization, the patient also did not experience any complication, such as bowel ischemia, pain, or fever. On the 4th day after endovascular embolization, her 


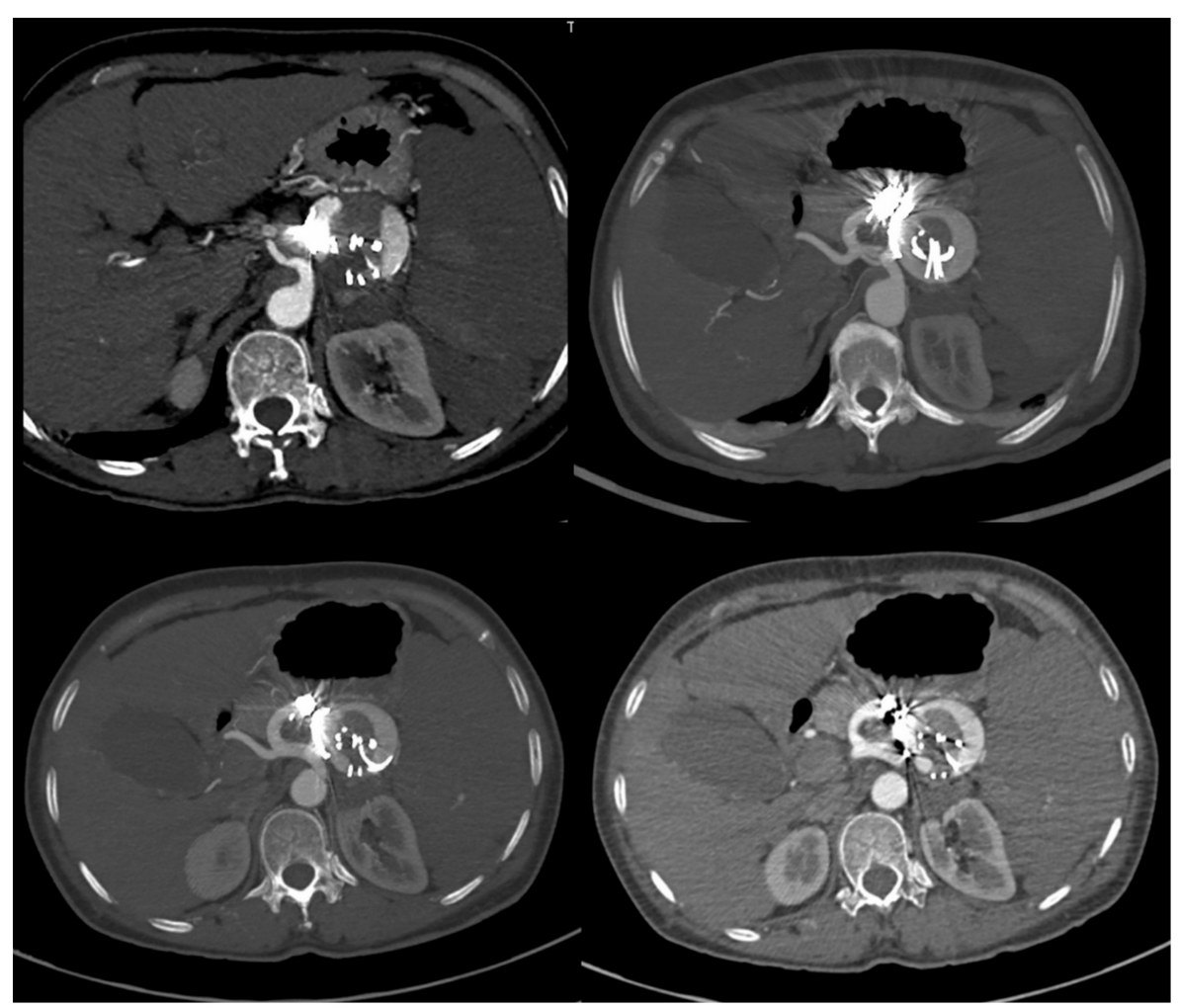

FIGURE 3 | CT-scan of the abdomen showed signs of blood flow into the embolized splenic aneurysm sac.

CT scan showed thrombosis in the aneurysm sac (Figure 3). One week after endovascular embolization, her white blood cell count was $3.74 \times 10^{9} / \mathrm{L}$ and her platelet count was $72 \times 10^{9} / \mathrm{L}$. Subsequently, we performed aneurysmectomy plus splenectomy without any blood transfusion during the process. The patient was not transferred to the intensive care unit. The patient's platelet count and white blood cell count normalized at 2 and 3 days after surgery, respectively. She recovered uneventfully and was discharged from the hospital 5 days after surgery. During her 6-months of follow-up, her platelet count remained normal and no adverse events occurred.

\section{DISCUSSION}

SAAs are usually asymptomatic and diagnosed incidentally. Currently, the guidelines recommend treating non-ruptured splenic artery true aneurysms $>3 \mathrm{~cm}$, with a demonstrable increase in size, or with associated symptoms in patients of acceptable risk because of the risk of rupture (1 C)(7). MSAAs is rarely and the treatment was challenging. To the best of our knowledge, there are only 36cases previously reported in 25 English medical literatures to the date of writing in a search of PubMed, Google Scholar, and Google databases (Table 1).

Currently, several treatment methods exist for treating SAA, including endovascular, laparoscopic, and open surgery. In recent years, endovascular therapy has been favored for being minimally invasive, offering rapid postoperative recovery, and providing a high comfort level to patients. Several endovascular treatment methods for SAA, mainly include coil embolization, placement of covered stents, plug deployment, gluing, and injection of endoluminal thrombin, polyvinyl alcohol, particles, or gel foam $(1,2,32,33)$. Endovascular therapy is preferred in cases involving surgical technical difficulty and in patients with high risk of open operative. In addition, this option is considered for lesions located in the artery proximal and ruptured aneurysm (34). Endovascular treatment options, such as transcatheter embolization, stents graft, plug deployment and injection of endoluminal thrombin, polyvinyl alcohol, particles, or gel foam, for SAAs depend on the aneurysm's dimension, location and anatomical parameters. However, the application of this technique is limited by intrasplenic MSAAs, infected (mycotic) SAA, tortuous arteries, decreased artery dimensions, and the location of the lesion.In addition, giant aneurysm was not suitable for endovascular treatment, as the aneurysm may involve the intestine, pancreas, and other neighboring organs. Owing to the increasing frequency of endovascular treatment, its main complications, such as coil and stent migration, splenic and intestinal infarction, hemorrhage and aneurysm rupture, fever, and splenic abscess and recanalization, have begun to attract the attention of clinicians (35-38).

Despite rapid advances in minimally invasive surgery, open abdominal surgery remains the gold standard for treatment. Open/laparoscopic surgery aneurysmectomy with/without splenectomy is still suitable for patients with distally located, 
TABLE 1 | Clinical and treatment features of the reported cases of multiple splenic artery aneurysms.

\begin{tabular}{|c|c|c|c|c|c|c|c|c|c|c|}
\hline References & $\#$ & $\begin{array}{l}\text { Age(years) } \\
\text { and sex }\end{array}$ & Possible etiology & Symptoms & Rupture & $\begin{array}{l}\mathrm{MD} / \\
(\mathrm{mm})\end{array}$ & Location & $\begin{array}{l}\text { Intrasplenic/ } \\
\text { hilum SAA }\end{array}$ & Treatment & $\begin{array}{l}\text { Outcome/ } \\
\text { Complication }\end{array}$ \\
\hline Matter, (8) & 12 & NA & $\begin{array}{l}\text { Liver cirrhosis PHT } \\
\text { Hypertension } \\
\text { Atherosclerosis Trauma }\end{array}$ & $\begin{array}{l}2 \text { cases: Cardiovascular collapse } \\
\text { with acute } \\
\text { a abdominal pain } 9 \text { cases: } \\
\text { symptomless }\end{array}$ & $\begin{array}{l}\text { eYes: } 2 \text { cases } \\
\text { No: } 10 \text { cases }\end{array}$ & 50 & $\begin{array}{l}\text { Distal third of } S A: 8 \\
\text { middle third of } S A: 4\end{array}$ & NA & $\begin{array}{l}\text { Splenectomy with splenic artery ligation:5, } \\
\text { close follow-up: } 7\end{array}$ & $\begin{array}{l}\text { Lost follow-up: } 1 \\
\text { died from } \\
\text { ruptured SAAs: } 2 \\
\text { survival: } 9 \\
\text { No complication }\end{array}$ \\
\hline Kitamura, (9) & 1 & $64 y, F$ & $\begin{array}{l}\text { Connective tissue } \\
\text { abnormalities }\end{array}$ & Left upper quadrant pain & Yes & 31 & Distal third of SA & Yes & Splenectomy with aneurysmectomy & Survival/No \\
\hline Cho, (10) & 1 & $54 y, M$ & Trauma & Abdominal discomfort & No & 45 & Intrasplenic & Yes & Splenectomy & Survival/No \\
\hline Juszkat, (11) & 1 & $60 y, F$ & NA & Vague upper abdominal pain & No & 25 & Distal third of SA & Yes & $\begin{array}{l}\text { Splenectomy with aneurysmectomy and } \\
\text { coil embolization }\end{array}$ & Survive/No \\
\hline Woo, (12) & 1 & $20 y, M$ & Unknown & Flank pain & No & 16 & Distal third of SA & No & Splenectomy with splenic artery ligation & Survival/No \\
\hline Ohmoto, (13) & 1 & $59 y, F$ & Liver cirrhosis PHT & Symptomless & No & 24 & Distal third of SA & No & Coil embolization & Survival/No \\
\hline Williamson, (14) & 1 & $71 y, F$ & Liver cirrhosis PHT & $\begin{array}{l}\text { Left upper quadrant pain and } \\
\text { pulsating sensation }\end{array}$ & No & NA & NA & NA & Splenectomy with splenic artery ligation & Survival/No \\
\hline Watada, (15) & 1 & $64 y, M$ & FD & Right lower abdominal pain & No & 40 & Distal third of SA & Yes & Splenectomy with splenic artery ligation & Survival/No \\
\hline Zubaidi, (16) & 1 & $42 y, F$ & Multiple pregnancies & $\begin{array}{l}\text { Left-sided abdominal pain } \\
\text { lightheadedness } \\
\text { vomiting hematemesis }\end{array}$ & Yes & 45 & Distal third of SA & Yes & Splenectomy with splenic artery ligation & Survival/No \\
\hline Al-abbal, (4) & 1 & 70y, M & NA & Left upper quadrant pain & No & 40 & $\begin{array}{l}\text { Proximal two- third of } \\
\text { SA }\end{array}$ & No & Coil embolization & Survival/No \\
\hline Phillips, (17) & 1 & $16 y, M$ & Liver cirrhosis PHT & Symptomless & No & 43 & Distal third of SA & Yes & Close follow-up & Survival/No \\
\hline Wang, (18) & 1 & $25 y, F$ & NA & $\begin{array}{l}\text { Left upper quadrant abdominal } \\
\text { pain, fever duration }\end{array}$ & No & 35 & Distal two- third of SA & Yes & Splenectomy with splenic artery ligation & Survival/No \\
\hline Manjunatha, (19) & & $16 y, F$ & PHT & $\begin{array}{l}\text { Vague abdominal pain } \\
\text { hematemesis abdominal mass }\end{array}$ & No & 18 & Distal third of SA & Yes & $\begin{array}{l}\text { Splenectomy, aneurysmectomy and } \\
\text { splenorenal shunt }\end{array}$ & Survival/No \\
\hline $\begin{array}{l}\text { Yakubovitch, } \\
2013(20)\end{array}$ & 1 & 32y, M & PHT & Acute onset of epigastric pain & Yes & 25 & Distal two- third of SA & Yes & $\begin{array}{l}\text { Splenectomy with aneurysmectomy and } \\
\text { coil embolization }\end{array}$ & Survival/No \\
\hline Aroor, (21) & 1 & $39 y, F$ & FD & Abdominal discomfort duration & No & 58 & Distal third of SA & Yes & NA & Survival/No \\
\hline Honda, (22) & 1 & $74 y, F$ & $\begin{array}{l}\text { Pneumococcal } \\
\text { pneumonia infection }\end{array}$ & Acute right upper quadrant pain & No & 35 & Intrasplenic & Yes & Coil embolization respectively & Survival/No \\
\hline Beksac, (6) & 1 & 23y, F & PHT & Symptomless & No & 70 & All segments & Yes & Aneurysmectomy with splenectomy & Survival/No \\
\hline Bizueto, (23) & 1 & $66 y, F$ & NA & Occasional abdominal pain & No & 90 & Distal third of SA & No & Aneurysmectomy with revascularization & Survival/No \\
\hline Termos, (24) & 1 & $54 y, F$ & Unknow & Left sided abdominal pain & No & 25 & Distal third of SA & No & Aneurysmectomy with splenectomy & Survival/No \\
\hline Bagga, (25) & 1 & $40 y, F$ & Liver cirrhosis PHT & NA & No & 20 & Distal two- third of SA & Yes & Close follow-up & Survival/No \\
\hline Niu, (26) & 1 & $57 y, F$ & Liver cirrhosis PHT & Symptomless & No & 27 & Distal two- third of SA & Yes & Coil embolization & Survival/No \\
\hline Rehman, (27) & 1 & $22 y, F$ & PHT & Left upper abdominal pain & No & 100 & Distal third of SA & Yes & Glue and coils embolization & Survival/No \\
\hline Sakamoto, (28) & 1 & 36y, M & FD DLC & Symptomless & No & 110 & Distal two- third of SA & Yes & Splenectomy with distal pancreatectomy & Survival/No \\
\hline Kawachi, (29) & 1 & $51 y, F$ & IPHT & NA & No & 20 & Distal third of SA & Yes & $\begin{array}{l}\text { Living donor liver transplantation and } \\
\text { splenectomy }\end{array}$ & Survival/No \\
\hline Selim, (30) & 1 & $39 y, F$ & Trauma & NA & No & 15 & Distal third of SA & Yes & Coil embolization & Survival/No \\
\hline Stoelting, (31) & 1 & $58 \mathrm{y}, \mathrm{F}$ & Multiple pregnancies & $\begin{array}{l}\text { Nausea, vomiting early satiety } \\
\text { weight loss }\end{array}$ & No & 60 & Distal two- third of SA & Yes & $\begin{array}{l}\text { Partial embolization and diagnostic } \\
\text { splenectomy }\end{array}$ & Survival/No \\
\hline
\end{tabular}

MD, maximum diameter in multiple splenic artery aneurysms; NA, not available; FD, Fibromuscular dysplasia; PHT, portal hypertension; IPHT, Idiopathic portal hypertension; DLC, decompensated liver cirrhosis. \# means number of patient. 
multiple SAAs, giant SAA, intrasplenic SAA, infectious SAA and elongated and tortuous SAA $(1,2,39,40)$. In addition, this method is also suitable for patients with failure of endovascular treatment, complications with endovascular treatment (e.g., splenic infarction and graft displacement.), severe splenic infarction, splenic abscess and abdominal dense adhesion $(1,2,33,40,41)$. Surgical treatment often involves the spleen, pancreas and other adjacent organs, and distal pancreatectomy is necessary. This depends on the dimensions of the lesion, coexisting morbidities (pancreatitis, cirrhosis, or portal hypertension), and the experience of the team $(1,2)$. However, the mortality and morbidity of open/ laparoscopic surgery are higher than those of endovascular treatment. Moreover, compared with endovascular surgery, open/laparoscopic surgery has the disadvantages of being more invasive, offering slower postoperative recovery and causing patients greater inconvenience. Laparoscopic surgery can be the optimal treatment and is minimally invasive, particularly when compared with open surgery, specifically in early pregnancy with smaller lesions. However, it is not applicable for giant aneurysm and having dense adhesion with surrounding tissues. Laparoscopic revascularization was not recommended. Extensive experience in endoscopic surgery was a prerequisite. There was no laparoscopic surgery in our literature review.

Our case, was of a patient having MSAAs with a giant sac, an intrasplenic aneurysm and a splenic hilum aneurysm. Considering the risk of splenic infarction, vascular recanalization and intrasplenic aneurysm rupture after endovascular embolization or stent graft, open abdominal surgery was initially planned. However, a patient with severe thrombocytopenia and leukopenia is a bad fit for open surgery. The prognosis of such patients may be poor when open surgery is abruptly performed. Partial embolization of splenic vessels is reportedly used to treat hypersplenism of thrombocytopenia, and partial splenic embolization is an effective method for improving the platelet count $(2,42-45)$. Embolization is primarily performed in the inflow and outflow tracts of aneurysms, and it is not necessary to completely embolize the aneurysm sac. After comprehensive consideration, endovascular partial embolization aneurysm was performed in the first step to relieve the patient's thrombocytopenia and leukopenia. Then aneurysmectomy with splenectomy was performed in the second step. Considering the

\section{REFERENCES}

1. Yagmur Y, Akbulut S, Gumus S, Demircan F. Giant Splenic Artery Pseudoaneurysm: A Case Report and Literature Review. Int Surg. (2015) 100:1244-8. doi: 10.9738/INTSURG-D-15-00043.1

2. Akbulut S, Otan E. Management of giant splenic artery aneurysm: comprehensive literature review. Medicine (Baltimore). (2015) 94:e1016. doi: 10.1097/MD.0000000000001016

3. Kassem MM, Gonzalez L. Splenic Artery Aneurysm. In: Treasure Island (FL): StatPearls (2020).

4. Al-Habbal Y, Christophi C, Muralidharan V. Aneurysms of the splenic artery - a review. Surgeon. (2010) 8:223-31. doi: 10.1016/j.surge.2009.11.011

5. Kalipatnapu S, Kota AA, Agarwal S. Giant splenic artery aneurysm. J Vasc Surg. (2019) 69:1940. doi: 10.1016/j.jvs.2019.02.039 patient had a giant aneurysm sac, intrasplenic aneurysm, splenic hilum aneurysm, and multiple aneurysms, we finally chose open abdominal aneurysmectomy with splenectomy and the patient achieved good results.

There is not a single treatment method suitable for all splenic aneurysms. A combination of several treatment techniques may be necessary for some cases, particularly for giant SAAs or patients with comorbid conditions. Endovascular therapy, laparoscopic surgery and open surgery options should be chosen after careful consideration of the patient's condition, which depends on several patient parameters, such as the age, sex, aneurysm dimension, aneurysm location, complications, and severity of the clinical findings. At the same time, we should also pay attention to regular monitoring, particularly after endovascular treatment.

\section{CONCLUSIONS}

Endovascular treatment, laparoscopic surgery, and open surgery are important methods of treating SAAs. The preferred treatment of an individual patient and aneurysm must be carefully based on the particular anatomy and any associated clinical conditions as well as the underlying condition of the patient. For patients with multiple SAAs, particularly SAAs at the hilar or intrasplenic locations, and for those with more severe comorbidities, endovascular embolization combined with open surgery may be a good treatment choice.

\section{DATA AVAILABILITY STATEMENT}

The original contributions presented in the study are included in the article/supplementary material, further inquiries can be directed to the corresponding author/s.

\section{AUTHOR CONTRIBUTIONS}

WC was the first authors and wrote the manuscript and was assistant in surgery. TW and DY was involved in editing the manuscript and assistant in surgery. JZ was chief operating surgeon. All authors contributed to the article and approved the submitted version.
6. Beksac K, Karakoc D. Multiple giant splenic artery aneurysms causing sinistral (left-sided) portal hypertension. Case Rep Gastrointest Med. (2016) 2016:6278452. doi: 10.1155/2016/6278452

7. Chaer RA, Abularrage CJ, Coleman DM, Eslami MH, Kashyap VS, Rockman C, et al. The Society for Vascular Surgery clinical practice guidelines on the management of visceral aneurysms. J Vasc Surg. (2020) 72:3S-39S. doi: 10.1016/j.jvs.2020.01.039

8. Mattar SG, Lumsden AB. The management of splenic artery aneurysms: experience with 23 cases. Am J Surg. (1995) 169:5804. doi: $10.1016 / \mathrm{S} 0002-9610(99) 80225-6$

9. Kitamura H, Nakayama K, Kitano T, Ozaki N, Nagaoka S. Removal of a splenic artery with a large aneurysm adhered to the pancreas without pancreatectomy: report of a case. Surg Today. (2002) 32:747-9. doi: 10.1007/s0059502 00141 
10. Cho YP, Han MS, Jang HJ, Kim JS, Lee SG. Traumatic multiple pseudoaneurysms of the intrasplenic artery: case report. $J$ Trauma. (2003) 54:1006-8. doi: 10.1097/01.TA.0000061493.80 633.EC

11. Juszkat R, Rowinska Z, Oszkinis G, Pukacki F, Brzezinski J. Combined surgical-endovascular treatment of multiple splenic artery aneurysms. Eur Radiol. (2004) 14:2364-5. doi: 10.1007/s00330-0042393-2

12. Woo EY, Fairman RM. Treatment of multiple visceral aneurysms in a 20-yearold patient. J Vasc Surg. (2004) 40:167-9. doi: 10.1016/j.jvs.2004.02.026

13. Ohmoto K, Yamamoto S. Treatment of multiple splenic aneurysms by coil embolization. AJR Am J Roentgenol. (2005) 185:5567. doi: 10.2214/ajr.185.2.01850556

14. Williamson JM, Sherman DI, Canelo R. Operative ligation of multiple splenic artery aneurysms. Int Surg. (2008) 93:261-4. doi: 10.1111/j.1365-263X.2007.00895

15. Watada S, Obara H, Shimoda M, Matsubara K, Matsumoto K, Kitajima M. Multiple aneurysms of the splenic artery caused by fibromuscular dysplasia. Ann Vasc Surg. (2009) 23:411 e415-417. doi: 10.1016/j.avsg.2008.04.015

16. Zubaidi A. Rupture of multiple splenic artery aneurysms: a common presentation of a rare disease with a review of literature. Saudi J Gastroenterol. (2009) 15:55-8. doi: 10.4103/1319-3767.45061

17. Phillips GS, Vo NJ, Ishak GE, Swanson JO, Otto RK. Splenic artery aneurysm: a diagnostic challenge in the setting of extensive portal venous collaterals. Pediatr Radiol. (2010) 40:1278-80. doi: 10.1007/s00247-009-1493-1

18. Wang H, Bie P, Zhang L, Chen G, Ding J, Chen Z. Multiple splenic artery aneurysms resulting in infarction of the spleen and regional portal hypertension. Pancreas. (2011) 40:7789. doi: 10.1097/MPA.0b013e318221fd41

19. Manjunatha YC, Prasad KN, Beeregowda YC, Bhaskaran A. Multiple splenic artery aneurysms secondary to extra hepatic portal vein obstruction. J Clin Diagn Res. (2013) 7:401-2. doi: 10.7860/JCDR/2013/4087.2781

20. Yakubovitch D, Halak M, Khaikin M, Silverberg D. Multiple splenic artery aneurysms in a patient with portal hypertension. Isr Med Assoc J. (2013) 15:55-6. doi: 10.1136/bmjopen-2012-002270

21. Aroor AR, Prakasha SR. U R, Attar NR. Multiple splenic artery aneurysms: a rare cause of extrahepatic portal hypertension and massive splenomegaly. J Clin Diagn Res. (2014) 8:MD01-02. doi: 10.7860/JCDR/2014/849 8.4821

22. Honda K, Saraya T, Yokoyama T, Goto H, Takizawa H. Multiple mycotic hepatic and splenic artery aneurysms in a patient with pneumococcal pneumonia: a case report with a review of the literature. Clin Case Rep. (2015) 3:891-6. doi: 10.1002/ccr3.369

23. Bizueto-Rosas H, Barajas-Colon JA. Delgadillo-de la OI, Malo-Martinez NP, Perez-Gonzalez HA, Hernandez-Perez NA. [Multiple aneurysms splenic; surgical exclusion with conservation of the spleen]. Cir Cir. (2016) 84:5864. doi: 10.1016/j.circen.2015.12.003

24. Termos S, Taqi A, Hayati H, Alhasan A, Alali M, Adi A. Segmental arterial mediolysis with 5 splenic artery aneurysms. A rare finding of a rare disease: Case report and literature review. Int J Surg Case Rep. (2017) 33:15862. doi: 10.1016/j.ijscr.2017.02.019

25. Bagga B, Das CJ. Multiple splenic artery aneurysms in non-cirrhotic hepatic fibrosis. BMJ Case Rep. (2019) 12. doi: 10.1136/bcr-2018-228705

26. Niu H, Junfeng S, Jianli A, Zibo Z, Yanchao D. Dual-interventional therapy for multiple splenic artery aneurysms in a patient with portal hypertension: A case report. Medicine (Baltimore). (2019) 98:e15205. doi: 10.1097/MD.0000000000015205

27. Rehman ZU. Multiple giant splenic artery aneurysms with hypersplenism and portal hypertension: a case report. Ann Vasc Dis. (2019) 12:2502. doi: 10.3400/avd.cr.19-00021

28. Sakamoto K, Ogawa K, Tamura K, Ueno $\mathrm{Y}$, Inoue H, Nakamura T, et al. Wilson disease with giant splenic artery aneurysms caused by fibromuscular dysplasia during living donor liver transplantation: a case report. Transplant Proc. (2019) 51:3131-5. doi: 10.1016/j.transproceed.2019.06.005

29. Kawachi S, Chiba N, Nakagawa M, Kobayashi T, Hikita K, Sano $\mathrm{T}$, et al. Living donor liver transplantation for idiopathic portal hypertension with extrahepatic portal vein stenosis and splenic artery aneurysms: a case report and review of the literature. BMC Surg. (2020) 20:257. doi: 10.1186/s12893-020-00921-6

30. Selim M, Awad Albayomy A, Almuhaish LA, Alraddadi SA, Alharbi WM. Multiple incidental unruptured splenic artery aneurysms following severe trauma. Cureus. (2020) 12:e11136. doi: 10.7759/cureus. 11136

31. Stoelting A, Esperti S, Balanchivadze N, Piacentino V, Mangano A Sarcoidosis presenting as massive splenomegaly and severe epistaxis, case report. Ann Med Surg (Lond). (2020) 54:6-9. doi: 10.1016/j.amsu.2020. 03.007

32. Zhu C, Zhao J, Yuan D, et al. Endovascular and surgical management of intact splenic artery aneurysm. Ann Vasc Surg. (2019) 57:75-82. doi: 10.1016/j.avsg.2018.08.088

33. Mariuba JVO. Splenic aneurysms: natural history and treatment techniques. J Vasc Bras. (2019) 19:e201 90058.

34. Wernheden E, Brenoe AS, Shahidi S. Emergency endovascular coiling of a ruptured giant splenic artery aneurysm. J Vasc Surg Cases Innov Tech. (2017) 3:240-2. doi: 10.1016/j.jvscit.2017. 10.008

35. Rebonato A, Maiettini D, Krokidis M, Graziosi L, Rossi M. Late migration of a covered stent into the stomach after repair of a splenic artery pseudoaneurysm. J Radiol Case Rep. (2016) 10:26-32. doi: 10.3941/jrcr.v10i 2.2620

36. Tekola BD, Arner DM, Behm BW. Coil migration after transarterial coil embolization of a splenic artery pseudoaneurysm. Case Rep Gastroenterol. (2013) 7:487-91. doi: 10.1159/0003 57151

37. Kingma KD, van der Linden AN, Roumen RM. Rebleeding of a splenic artery aneurysm after coil embolisation. Case Rep Surg. (2016) 2016:1858461. doi: 10.1155/2016/1858461

38. Pratap A, Pokala B, Vargas LM, Oleynikov D, Kothari V. Laparoscopic endoscopic combined surgery for removal of migrated coil after embolization of ruptured splenic artery aneurysm. J Surg Case Rep. (2018) 2018:rjx242. doi: 10.1093/jscr/r jx242

39. Hogendoorn W, Lavida A, Hunink MG, Moll FL, Geroulakos G, Muhs BE, et al. Open repair, endovascular repair, and conservative management of true splenic artery aneurysms. J Vasc Surg. 2014;60(6):1667-1676 e1661. doi: 10.1016/j.jvs.2014. 08.067

40. Fang G, Chen B, Fu W, Guo D, Xu X, Jiang J, et al. Strategies for endovascular treatment of complicated splenic artery aneurysms. J Vasc Surg. (2018) 68:787-94. doi: 10.1016/j.jvs.2017. 12.053

41. Tiberio GA, Bonardelli S, Gheza F, Arru L, Cervi E, Giulini SM. Prospective randomized comparison of open versus laparoscopic management of splenic artery aneurysms: a 10-year study. Surg Endosc. (2012). doi: 10.1007/s00464-012-2413-2

42. Cai M, Huang W, Lin C, Li Z, Qian J, Huang M, et al. Partial splenic embolization for thrombocytopenia in liver cirrhosis: predictive factors for platelet increment and risk factors for major complications. Eur Radiol. (2016) 26:370-80. doi: 10.1007/s00330-0153839-4

43. Tahara H, Takagi H, Sato K, Shimada $Y$, Tojima H, Hirokawa T, et al. A retrospective cohort study of partial splenic embolization for antiviral therapy in chronic hepatitis $\mathrm{C}$ with thrombocytopenia. J Gastroenterol. (2011) 46:1010-9. doi: 10.1007/s00535-0110407-9

44. Sato N, Beppu T, Kinoshita K, Yuki H, Suyama K, Yuruki H, et al. Partial splenic embolization for lenvatinib therapy-associated thrombocytopenia among patients with hepatocellular carcinoma. Anticancer Res. (2019) 39:6895-901. doi: 10.21873/anticanres. 13909

45. Liu J, Sun X, Ganguli S, Wehrenberg-Klee EP, Bhan I, Zhao Y, et al. Partial splenic embolization is superior to intravenous somatostatin for decreasing portal pressure in cirrhotic patients: a dynamic self-controlled cohort study. 
Scand J Gastroenterol. (2020) 55:1341-6. doi: 10.1080/00365521.2020.18 31589

Conflict of Interest: The authors declare that the research was conducted in the absence of any commercial or financial relationships that could be construed as a potential conflict of interest.

Publisher's Note: All claims expressed in this article are solely those of the authors and do not necessarily represent those of their affiliated organizations, or those of the publisher, the editors and the reviewers. Any product that may be evaluated in this article, or claim that may be made by its manufacturer, is not guaranteed or endorsed by the publisher.

Copyright $\odot 2022$ Chen, Wang, Yuan and Zhao. This is an open-access article distributed under the terms of the Creative Commons Attribution License (CC BY). The use, distribution or reproduction in other forums is permitted, provided the original author(s) and the copyright owner(s) are credited and that the original publication in this journal is cited, in accordance with accepted academic practice. No use, distribution or reproduction is permitted which does not comply with these terms. 